\title{
ANÁLISE DE VARIÂNCIA DE BLOCOS SOBRE DUAS ESTACAS COM CÁLICE EMBUTIDO, SUBMETIDOS À AÇÃO DE FORÇA DE COMPRESSÃO CENTRADA
}

\section{VARIANCE ANALYSIS OF TWO PILE CAPS WITH SOCKET EMBEDDED SUBJECT THE COMPRESSION CENTERED}

\author{
Rodrigo Gustavo Delalibera ${ }^{1}$, José Samuel Giongo²
}

Recebido em 13 de agosto de 2012; recebido para revisão em 30 de agosto de 2012; aceito em 01 de setembro de 2012; disponível on-line em 04 de setembro de 2012.

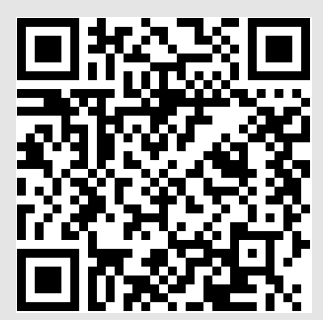

PALAVRAS CHAVES:

Blocos sobre estacas;

Fundações;

Concreto pré-moldado.

\section{KEYWORDS:}

Pile caps;

Foudations;

Precast concret.

* Contato com os autores:

11e-mail : delalibera@pq.cnpq.br (R. G. Delalibera)

Prof. Dr. do Curso de Engenharia Civil, Campus Catalão - Universidade Federal de Goiás.

22e-mail : jsgiongo@sc.usp.br (J. S. Giongo)

Prof. Dr. do Departamento de Engenharia de Estruturas, Escola de Engenharia de São Carlos - Universidade de São Paulo. é alterado se for considerada ou não a rugosidade na interface pilar-cálice. Com intuito de analisar o comportamento de blocos sobre duas estacas com cálice embutido, considerando a rugosidade da interface pilar-cálice, submetido à ação de força normal centrada de compressão, realizou-se uma análise de variância, baseada em resultados de simulações numéricas, feitas com auxílio de programa de computador baseado no método dos elementos finitos - MEF. Na análise numérica as não-linearidades físicas dos materiais concreto e aço foram consideradas, como também o atrito entre as interfaces paredes do pilar e do cálice. Considerou-se atrito perfeito entre as barras de aço das armaduras com o concreto do entorno. Observouse que o comprimento de embutimento do pilar no interior do bloco é fator preponderante no comportamento estrutural do elemento em análise.

ABSTRACT: The structural behavior of pile caps with socket embedded is modified if it is considered or not the friction between column and the socket. With intent to analyzer the behavior of the two pile caps with socket embedded, considering the friction between the column and the socket, with normal compression load, the variance analysis was realized, using in numerical simulations, development in computer program based in the finite element method - fem. In the numerical analysis the non-linearity material was considered, also the friction between the column and the socket. It was considered perfect friction between the reinforcement concrete and the concrete of around. It was observed that the length of inlay the column inside the pile cap is preponderant factor in the structural behavior of the element analyzed. 


\section{INTRODUÇÃO}

A escolha do tipo de fundação é feita após análise que considere as condições técnicas e econômicas da obra. As fundações em estacas são adotadas quando o solo em suas camadas superficiais não é capaz de suportar ações oriundas da superestrutura, sendo necessário, portanto, considerar resistência em camadas profundas. Ao se utilizar solução em fundação profunda por estacas, faz-se necessário a construção de outro elemento estrutural, o bloco de coroamento, também denominado bloco sobre estacas.

Segundo a ABNT NBR 6118:2007, blocos sobre estacas são importantes elementos estruturais cuja função é transferir as ações da superestrutura para um grupo de estacas. Esses elementos estruturais, apesar de serem fundamentais para a segurança da superestrutura, geralmente não permitem a inspeção visual quando em serviço, sendo assim, é importante o conhecimento de seu real comportamento nos Estados Limites de Serviço e Último. A Figura 1 ilustra esse elemento estrutural.

Quando a superestrutura é pré-moldada faz-se necessário que o pilar seja embutido no bloco. 0 comprimento de embutimento do pilar no interior do bloco, para que o mesmo seja considerado engastado, é função das ações transferidas pelo pilar (momento, forças vertical e horizontal) e do tipo de conformação superficial das paredes (rugosa ou lisa) do cálice e do pilar pré-moldado. Os comprimentos de embutimento são definidos pela ABNT NBR 9062:2006.

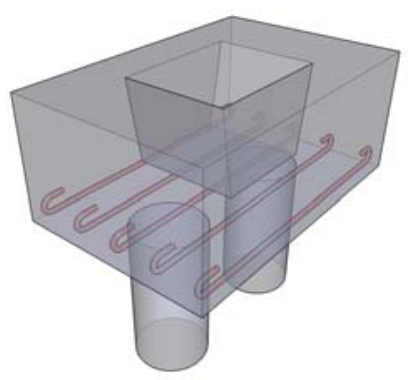

Figura 1: Detalhe esquemático das armaduras dos blocos analisados.

Existem algumas variações nos tipos de blocos com cálice (cálice externo, cálice parcialmente embutido e cálice totalmente embutido). A Figura 2 mostra as variações dos blocos sobre estacas para pilares prémoldados. O meio técnico utiliza com maior intensidade os blocos com cálice externo e parcialmente embutido.

O código europeu (EUROCODE 2) EN 1992-1-1 (2004) apresenta recomendações a respeito do projeto de cálice para ligação pilar-fundação, considerando o comportamento monolítico do conjunto quando se utiliza chave de cisalhamento. Para conformação lisa das paredes do cálice e do pilar, indica que o coeficiente de atrito entre as faces do pilar e as faces do cálice seja maior que 0,3 e o comprimento de embutimento do pilar maior ou igual a 1,2 vez a dimensão do pilar.

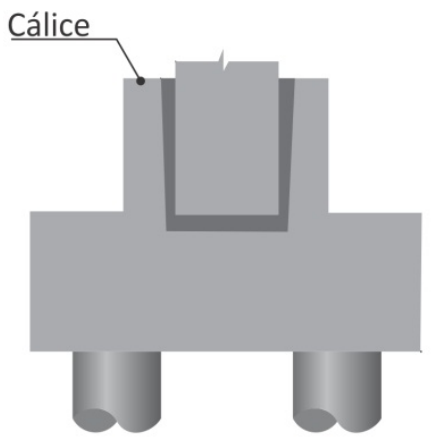

Cálice externo
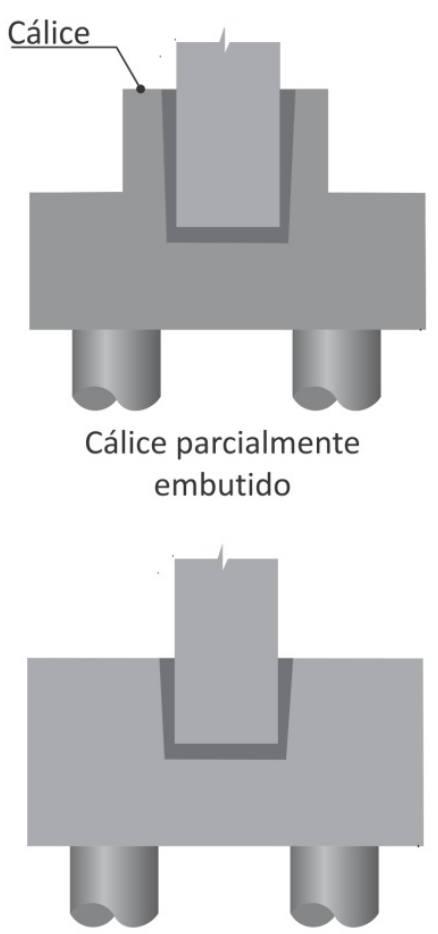

Cálice embutido

Figura 2: Blocos com cálice.

Como não há consenso junto aos meios técnico e científico com relação à seção do bloco onde se forma a escora (ou biela), realizou-se análise numérica, com intuito de observar o comportamento estrutural dos blocos. Foram analisados numericamente dezoito blocos sobre duas estacas, nove com interface rugosa e nove com interface lisa. O comprimento de embutimento do pilar $\left(\ell_{\mathrm{emb}}\right)$ e a espessura da laje de fundo do bloco $\left(h_{s}\right)$ foram variados. Assim, os comprimentos de embutimento dos pilares prémoldados foram iguais a $80 \mathrm{~cm}, 60 \mathrm{~cm}$ e $50 \mathrm{~cm}$. As espessuras da laje de fundo foram iguais a $30 \mathrm{~cm}, 20 \mathrm{~cm}$ e $10 \mathrm{~cm}$.

Neste trabalho somente são apresentados os resultados dos modelos analisados com força normal centrada. 


\subsection{Objetivo}

Analisar o comportamento de estruturas de blocos sobre duas estacas com cálice embutido, com interfaces lisa e rugosa das paredes dos pilar e do cálice, submetido à ação de força vertical de compressão centrada e, verificar por meio de análise de variância, qual a variável apresenta maior relevância no comportamento dos mesmos.

\subsection{Método}

O método empregado foi o relativo a trabalhos com ênfase em análise numérica. Definidos os modelos que foram estudados, análise estatística foi desenvolvida, utilizando valores obtidos por meio de simulações numéricas. Os blocos de concreto armado sobre estacas foram analisados numericamente por meio de programa de computador baseado nos métodos dos elementos finitos - MEF. As não-linearidades física e geométrica foram consideradas. A fissuração do concreto e a armadura do bloco também foram levadas em consideração. Para a análise numérica dos blocos via método dos elementos finitos, utilizou-se o programa ANSYS (ANalyser SYStem).

\section{PROPRIEDADES GEOMÉTRICAS DOS MODELOS ANALISADOS NUMERICAMENTE}

Os modelos foram dimensionados com os critérios de BLÉVOT \& FRÉMY (1967). As taxas de armadura foram fixadas, pois não eram objetos de análise. A distância entre os eixos das estacas também foi fixada, variando-se o comprimento de embutimento do pilar $\left(\ell_{\mathrm{emb}}\right)$ e a espessura da laje de fundo do bloco $\left(h_{s}\right)$. O dimensionamento das barras de aço da armadura principal de tração do bloco e as verificações da diagonal comprimida junto à zona nodal inferior (bloco-estaca) e junto à zona nodal superior (bloco-pilar) foram feitos de acordo com as recomendações do modelo proposto por BLÉVOT \& FRÉMY (1967). Utilizaram-se como limites para verificação das tensões junto às zonas nodais superior e inferior os valores sugeridos pelos pesquisadores franceses, ou seja, $1,40 \cdot f_{c k}$ junto ao pilar e $f_{c k}$ junto à estaca. Todas as recomendações prescritas na ABNT NBR 6118:2007 e na ABNT NBR 9062:2006 foram consideradas.

Optou-se por utilizar ancoragem reta, pois se verificou por meio das recomendações da ABNT NBR 6118:2007 que o gancho não era necessário (critérios de ancoragens em apoios extremos de vigas). Ao admitir essa hipótese não foi considerada a recomendação da
ABNT NBR 6118:2007 que exige a utilização de ganchos em blocos sobre estacas. Lembram-se os resultados obtidos por Delalibera (2006) que mostraram, nos casos analisados, que as deformações nas barras da armadura na região da ligação com a estaca são de pequena intensidade.

Para o dimensionamento dos blocos, utilizouse um bloco padrão, ou seja, todos os blocos tiveram as mesmas dimensões em planta do bloco padrão, variando-se apenas os comprimento de embutimento do pilar $\left(\ell_{\mathrm{emb}}\right)$ e a espessura da laje de fundo do bloco $\left(h_{s}\right)$. Subentende-se, então, que as alturas totais dos modelos e os ângulos de inclinação da biela de compressão também sofreram variações. Para o bloco padrão adotaram-se estacas de seção transversal quadrada igual a $30 \mathrm{~cm}$ de lado, pilar também com seção transversal quadrada, porém com $40 \mathrm{~cm}$ de lado. O comprimento de embutimento do pilar no bloco padrão foi igual a $60 \mathrm{~cm}$. Esse valor representa o comprimento mínimo de embutimento para paredes lisas (cálice e pilar) especificado na ABNT NBR 9062:2006, quando a relação $\left[M_{d} /\left(N_{d} \cdot h\right)\right] \leq 0,15$. A Figura 3a apresenta as propriedades geométricas do bloco padrão e Figura $3 \mathrm{~b}$ os fatores que apresentaram variações na análise numérica.

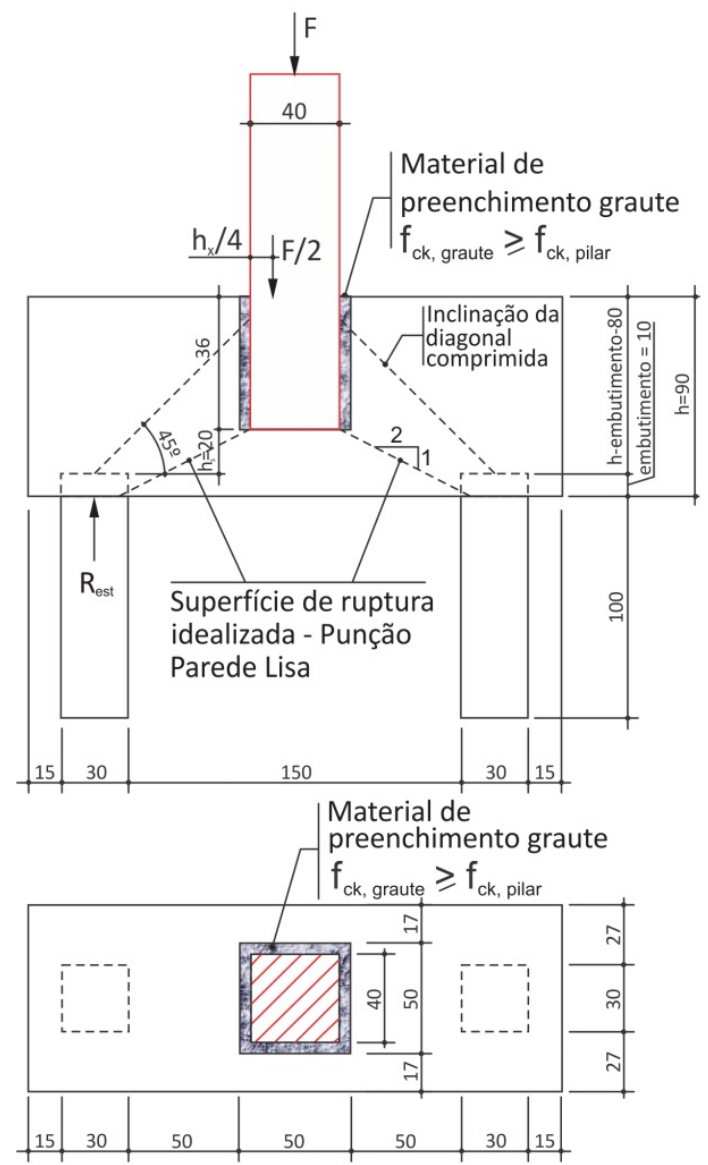

a. Propriedades geométricas do bloco padrão. Figura 3a: Bloco padrão. 


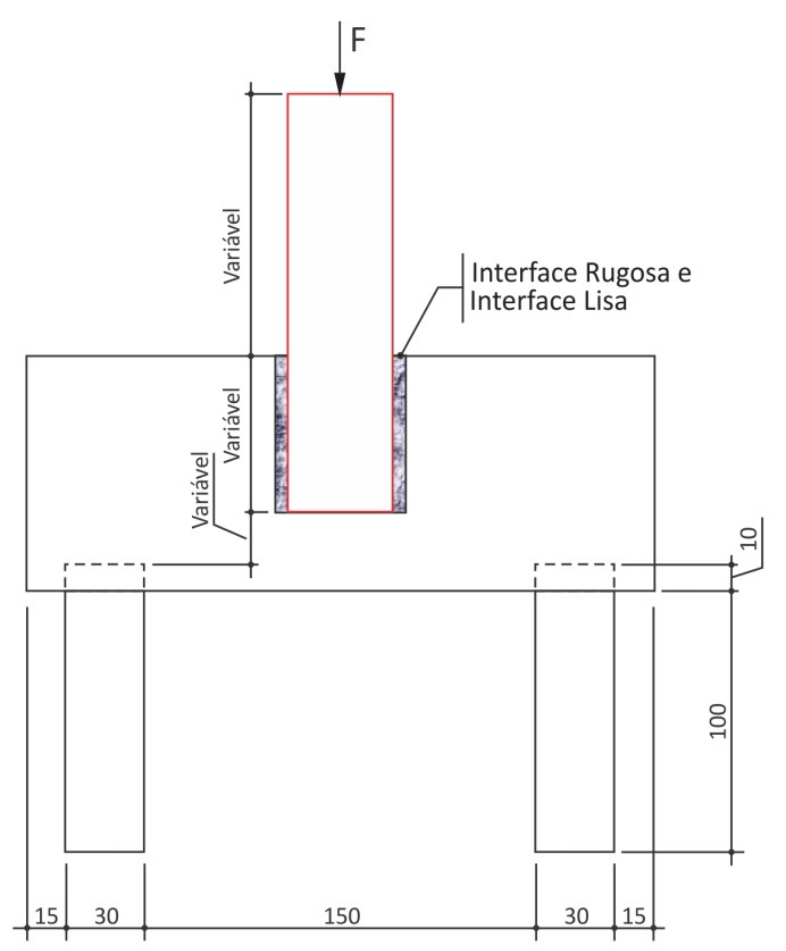

Força Normal

Parede Rugosa

Parede Lisa

b. Propriedades variáveis na análise numérica do bloco padrão.

Figura 3b: Bloco padrão.

A distância entre os eixos das estacas foi determinada em função do ângulo limite inferior estabelecido pelos pesquisadores franceses, ou seja, $45^{\circ}$. Portanto, a altura total do bloco padrão foi igual a $90 \mathrm{~cm}$, e as dimensões em plantas foram iguais a $240 \mathrm{~cm}$ por 84 $\mathrm{cm}$.
O comprimento de embutimento das estacas na face inferior do bloco seguiu sugestão de MONTOYA et al. (2000), ou seja, embutiu-se dez centímetros do fuste da estaca no interior do bloco.

Com relação aos pilares e as estacas adotaramse resistências características do concreto à compressão igual a $50 \mathrm{MPa}$ procurando evitar assim, ruína desses elementos. As armaduras das estacas foram compostas por oito barras de aço com diâmetro de $20 \mathrm{~mm}$ e resistência característica de escoamento igual a 500 $\mathrm{MPa}$, totalizando área de aço igual a $25,1 \mathrm{~cm}^{2}$. Os pilares foram discretizados com doze barras de $20 \mathrm{~mm}$ e resistência característica de escoamento também igual a $500 \mathrm{MPa}$, totalizando área de aço igual a $32,7 \mathrm{~cm}^{2}$.

Para o material de preenchimento, adotou-se resistência característica à compressão igual a $50 \mathrm{MPa}$ (valor igual à resistência característica do concreto do pilar).

O Quadro 1 apresenta as propriedades dos blocos analisados com relação à conformação das paredes lisas e com chave de cisalhamento (rugosa), solicitada pela força de compressão supostamente centrada no pilar.

A nomenclatura utilizada no Quadro 1 é descrita: L, blocos com conformação lisa das paredes do cálice e do pilar; $R$, conformação rugosa das paredes do cálice e do pilar; $\ell_{\mathrm{e}} 80$, embutimento do pilar igual a oitenta centímetros (demais número são análogos); $h_{s} 30$, espessura da laje de fundo igual a trinta centímetros (demais números são análogos); N significa que foi aplicada força de compressão centrada.

Na mesma tabela A distância entre os eixos das estacas de todos os blocos foi igual a cento e oitenta centímetros. Utilizando as indicações de Blévot \& Frémy (1967), fez-se uma previsão das capacidades resistentes dos blocos.

\begin{tabular}{|c|c|c|c|c|c|c|c|c|c|}
\hline Blocos & $\begin{array}{c}\text { Altura } \\
\text { total } \\
\text { h } \\
(\mathrm{cm}) \\
\end{array}$ & $\begin{array}{l}\text { Medida } \\
\text { dos lados } \\
\text { do pilar } \\
\text { (cm) }\end{array}$ & $\begin{array}{c}\text { Medida } \\
\text { dos lados } \\
\text { da estacas } \\
(\mathrm{cm})\end{array}$ & $\begin{array}{c}A_{\text {st }} \\
\left(\mathrm{cm}^{2}\right)\end{array}$ & $\begin{array}{l}B_{1 x} \\
(\mathrm{~cm})\end{array}$ & $\begin{array}{l}B_{\mathrm{ly}} \\
(\mathrm{cm})\end{array}$ & $\begin{array}{l}\ell_{e m b} \\
(\mathrm{~cm})\end{array}$ & $\begin{array}{c}h_{s} \\
(\mathrm{~cm})\end{array}$ & $\begin{array}{c}\text { Classificação ABNT } \\
\text { NBR 6118:2007 }\end{array}$ \\
\hline $\begin{array}{l}\text { Lle80hs30N } \\
\text { Rle80hs30N }\end{array}$ & 110 & $40 \times 40$ & $30 \times 30$ & 22 & 240 & 84 & 80 & 30 & Rígido \\
\hline $\begin{array}{l}\text { Lle80hs20N } \\
\text { Rle80hs20N }\end{array}$ & 100 & $40 \times 40$ & $30 \times 30$ & 22 & 240 & 84 & 80 & 20 & Rígido \\
\hline $\begin{array}{l}\text { Lle80hs10N } \\
\text { Rle80hs10N }\end{array}$ & 90 & $40 \times 40$ & $30 \times 30$ & 22 & 240 & 84 & 80 & 10 & Rígido \\
\hline $\begin{array}{l}\text { Lle60hs30N } \\
\text { Rle60hs30N }\end{array}$ & 90 & $40 \times 40$ & $30 \times 30$ & 22 & 240 & 84 & 60 & 30 & Rígido \\
\hline $\begin{array}{l}\text { Lle60hs20N } \\
\text { Rle60hs20N }\end{array}$ & 80 & $40 \times 40$ & $30 \times 30$ & 22 & 240 & 84 & 60 & 20 & Rígido \\
\hline $\begin{array}{l}\text { Lee60hs10N } \\
\text { Rle60hs10N }\end{array}$ & 70 & $40 \times 40$ & $30 \times 30$ & 22 & 240 & 84 & 60 & 10 & Rígido \\
\hline $\begin{array}{l}\text { Lee50hs30N } \\
\text { Rle50hs30N }\end{array}$ & 80 & $40 \times 40$ & $30 \times 30$ & 22 & 240 & 84 & 50 & 30 & Rígido \\
\hline $\begin{array}{l}\text { Lle50hs20N } \\
\text { Rle50hs20N }\end{array}$ & 70 & $40 \times 40$ & $30 \times 30$ & 22 & 240 & 84 & 50 & 20 & Rígido \\
\hline $\begin{array}{l}\text { Lle50hs10N } \\
\text { Rle50hs10N }\end{array}$ & 60 & $40 \times 40$ & $30 \times 30$ & 22 & 240 & 84 & 50 & 10 & Rígido \\
\hline
\end{tabular}

$A_{\mathrm{st}}$ representa a área da seção transversal das barras de aço classe CA-50, $\mathrm{B}_{\mathrm{lx}}$ o comprimento do bloco, $\mathrm{B}_{\mathrm{ly}}$ a largura do bloco, $\ell_{\mathrm{emb}}$ o comprimento de embutimento do pilar pré-moldado e $h_{s}$ a espessura da laje de fundo do bloco. 


\section{ANÁLISE NUMÉRICA}

O objetivo da análise numérica foi fornecer resultados para a aplicação do critério ANOVA (análise de variância), sendo assim, blocos sobre duas estacas com cálice embutido, com conformação das paredes lisas e rugosas foram analisados. A análise numérica não tinha como objetivo calibrar curvas de resultados experimentais, mas sim, apresentar tendências de comportamento dos modelos analisados. A geometria de todos os modelos foram criadas no programa de computador AutoCad $^{\circledR}$ (versão 2007) e exportadas para - programa de computador ANSYS ${ }^{\circledR}$, por meio de extensão SAT. A Figura 4 apresenta a rede de elementos finitos utilizadas para a discretização dos elementos de volume (concreto) e os elementos de barra (barras de aço das armaduras).

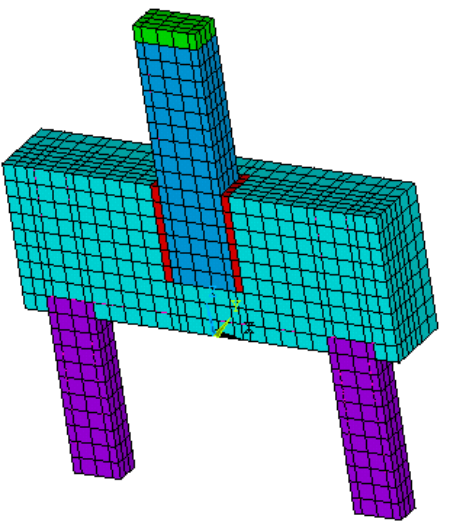

a. Concreto.

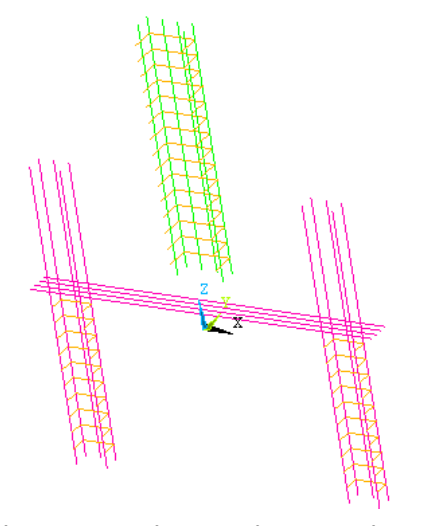

b. Barras de aço da armadura.

Figura 4: Discretização utilizada nos modelos.

A força de compressão foi aplicada por meio de pressão no topo do pilar. Como os modelos eram simétricos, utilizou-se o recurso de simetria. Portanto, analisou-se apenas metade do elemento estrutural. Restringiram-se as translações (nas três direções, $x, y$ e $z$ ) dos nós dos elementos posicionados nas pontas das estacas.
A Figura 5 apresenta as condições de contorno empregadas nos modelos.

O comprimento de um metro das estacas e do pilar, foi escolhido em função do princípio de Saint Venant, assim, eliminaram-se as influências das perturbações de tensões nas regiões de aplicação das forças e nas regiões de restrições de translações.

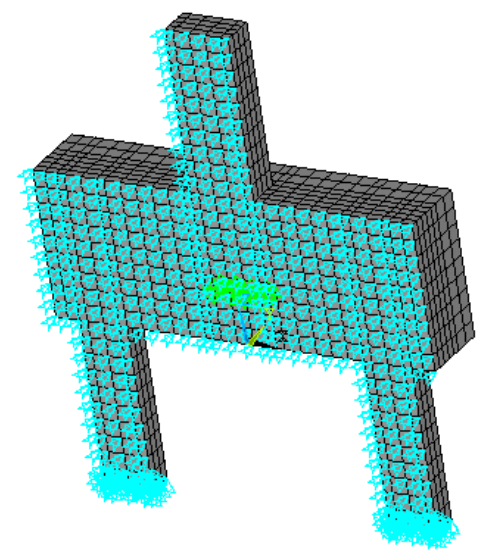

Figura 5: Condições de contorno e rede de elementos finitos.

\subsection{Elementos Finitos Utilizados}

Para a modelagem do material concreto, utilizou-se o elemento finito Solid 65. Esse elemento possui oito nós com três graus de liberdade por nó translações nas direções $x$, y e z. 0 elemento apresenta deformações plásticas, fissuração e esmagamento em três direções ortogonais. No elemento Solid 65, a fissuração ocorre quando a tensão principal de tração em qualquer direção atinge a superfície de ruptura. Depois da fissuração, o módulo de elasticidade do concreto tem valor igual a zero na direção considerada. A ruptura ocorre quando todas as tensões de compressão atingem a superfície de ruptura, subseqüentemente, o módulo de elasticidade tem valor igual a zero em todas as direções. A Figura 6 apresenta o elemento Solid 65.

Na modelagem das barras de aço da armadura foi utilizado o elemento finito Link 8. Esse elemento tem dois nós, sendo que cada nó possui três graus de liberdade - translações nas direções x, y e z. A Figura 7 mostra esse elemento. Optou-se por esse elemento, pois as armaduras nos modelos eram discretas.

Nos modelos, não foi considerado o fenômeno da aderência entre as barras de aço e o concreto. Apesar disso, os resultados das comparações entre resultados experimentais e numéricos mostraram-se satisfatórios.

Para representar o atrito entre as paredes do cálice e o material de preenchimento (graute) e o 
material de preenchimento (graute) e as faces do pilar pré-moldados, utilizaram-se elementos de contato, definindo-se superfícies de contato entre os materiais (superfície de contato e superfície alvo). As superfícies de contato entre os materiais foram representadas por dois elementos finitos, denominado "par de contato". Para a superfície de contato, utilizou-se o elemento finito Contato 173 e para a superfície alvo, utilizou-se o elemento finito Target 170 . Esses elementos possuem três graus de liberdade em cada nó e as propriedades geométricas são as mesmas das faces dos elementos sólidos aos quais estão ligados, podendo ter geometria triangular ou quadrangular. A Figura 8 apresenta os pares de contado (elemento Contato 173 e Target 170).

Os elementos finitos de contato foram utilizados apenas nos modelos com conformação das paredes do cálice e o pilar lisa, pois, em virtude de pesquisas já realizadas por diversos pesquisadores, pode-se considerar que a ligação pilar-fundação por meio de cálice com chave de cisalhamento tenha comportamento monolítico.

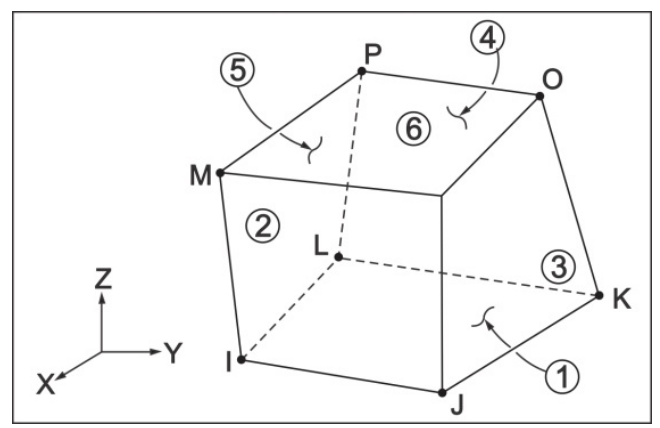

Figura 6: Solid 65, Ansys ${ }^{\circledR}$ (2011).

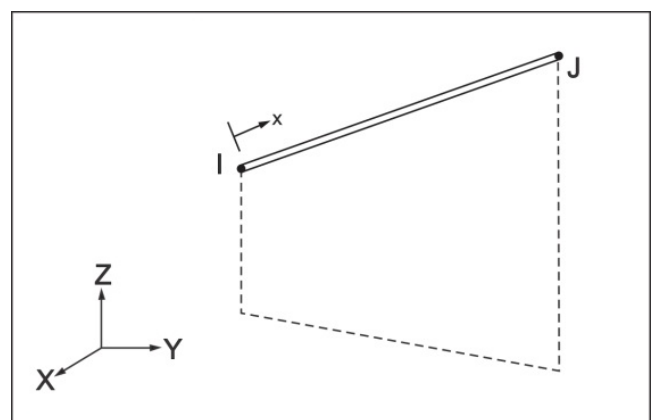

Figura 7: Link 8, Ansys ${ }^{\circledR}(2011)$.

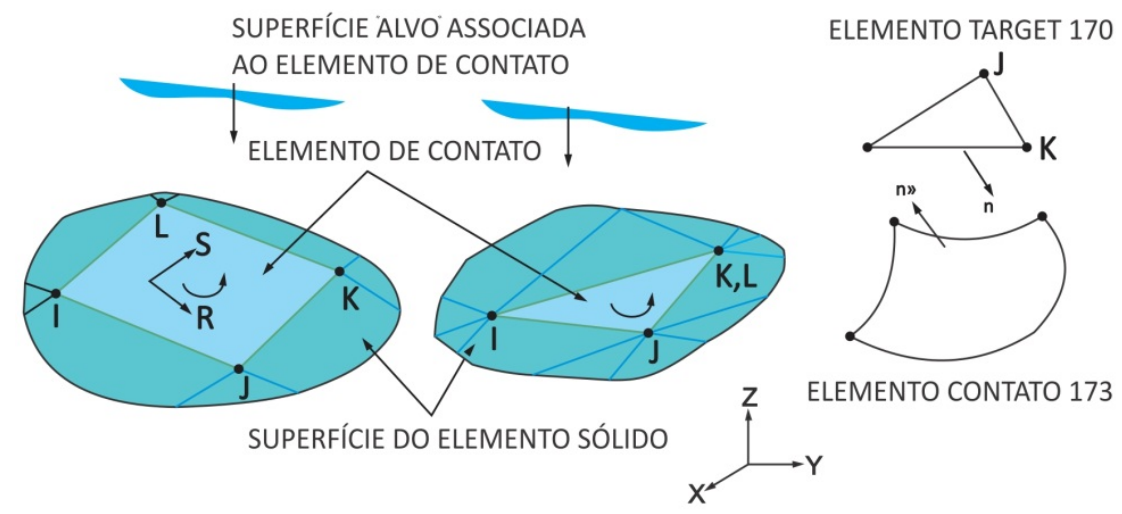

Figura 8: Elementos finitos de contato.

\subsection{Propriedades dos materiais}

Desenvolver um modelo capaz de representar o comportamento do concreto o mais próximo do comportamento real é um desafio. O concreto armado é um material quase-frágil e tem diferentes comportamentos na compressão e na tração.

Na compressão, a curva tensão vs. deformação do concreto é elástica e linear até aproximadamente $30 \%$ da força última de compressão. Após esse ponto, o concreto perde rigidez e segue elevando os valores das tensões até a força de ruptura. Depois disso, não há aumento da tensão sofrendo amolecimento. Na tração, a curva tensão vs. deformação do concreto é aproximadamente elástica e linear até a tensão de tração máxima. Após esse ponto, o concreto fissura e sua resistência é nula.
Para modelar o material concreto, é necessário fornecer ao programa Ansys ${ }^{\circledR}$ os seguintes dados de entrada: módulo de elasticidade longitudinal do concreto; resistências últimas do concreto à compressão e à tração; coeficiente de Poisson; e coeficientes de transferência de cisalhamento. O Ansys $^{\circledR}$ também permite como dado de entrada, a inclusão de uma curva tensão vs. deformação para representar as propriedades mecânicas do concreto. Isso normalmente é feito, quando por problemas de convergência, o processamento é interrompido bruscamente por ruptura precoce do concreto. Kachlakev et al. (2001) apresentam mais informações a respeito desse fenômeno. Nos modelos analisados, não ocorreu esse problema.

O módulo de elasticidade longitudinal do concreto, $E_{c}$, como também, a resistência característica 
à tração, $f_{c t k}$, foram determinadas com base nas recomendações da ABNT NBR 6118:2007. O coeficiente de Poisson, $v$, adotado para o concreto foi igual a 0,2 e os coeficientes de transferência de cisalhamento, $\beta$ adotados foram iguais a 1 para fissuras abertas e fechadas. Os coeficientes $\beta$ utilizaram esse valor, pois testes feitos demonstraram maior eficiência na convergência do processamento quando utilizou-se o valor mencionado.

Foi utilizado o critério de ruptura Concrete fornecido pelo Ansys ${ }^{\circledR}$. Para a definição da superfície de ruptura se fazem necessários apenas dois parâmetros: as resistências à compressão e à tração últimas do concreto. O critério de ruptura Concrete é análogo ao critério de ruptura de Willam-Warnke. A Figura 9 apresenta a superfície de ruptura. Em todos os blocos adotaram-se resistência característica do concreto à compressão $\left(f_{c k}\right)$ igual a $25 \mathrm{MPa}$.

Para as barras de aço, adotou-se comportamento elastoplástico perfeito. O módulo de elasticidade utilizado foi igual a $210 \mathrm{GPa}$, o coeficiente de Poisson igual a 0,3 e a resistência característica ao escoamento igual a $500 \mathrm{MPa}$. Por meio de testes realizados, constatou-se que o critério de NewtonRaphson foi o que apresentou melhores resultados quanto à convergência dos modelos, sendo assim, em todas as análises utilizou-se esse critério.

Para as propriedades dos elementos de contato, utilizou-se o modelo de atrito de Coulomb, sendo necessário definir o valor do coeficiente de atrito $\mu$, as tensões máximas de cisalhamento, $\tau_{\text {máx }}$ e duas constantes, FKN e FTOLN. FKN representa um coeficiente de rigidez normal do elemento de contato e a constante FTOLN é um fator de tolerância a ser aplicado no sentido do vetor normal da superfície. Esse fator é utilizado para determinar a compatibilidade da penetração. A compatibilidade do contato é satisfeita se a penetração estiver dentro de uma tolerância permissível (FTOLN mede a profundidade de elementos subjacentes). A profundidade é definida pela profundidade média de cada elemento individual do contato no par. Se o programa de computador Ansys ${ }^{\circledR}$ detectar qualquer penetração maior do que esta tolerância, a solução global não converge, mesmo que as forças residuais e os incrementos de deslocamento se encontrem dentro dos critérios da convergência adotada. Para o coeficiente FKN utilizou-se valor igual a 1 e para FTOL valor igual 0,1.

A escolha do valor "correto" do coeficiente de atrito é uma tarefa difícil, pois o mesmo depende de vários fatores, tais como: tipo de superfície, intensidades das ações, propriedades mecânicas dos materiais que compõem a ligação pilar-fundação, como o concreto do bloco, o concreto do pilar e o concreto do preenchimento. Existe na literatura técnica indicações para o valor do coeficiente de atrito concreto-concreto. Segundo Nielsen (1984) o valor a ser utilizado é 0,6, a EN 1992-1-1 (2004) indica que o valor do coeficiente de atrito para a situação em que a ligação pilar-fundação por meio cálice com paredes lisas, deve ser maior que 0,3. Canha (2004) e Ebeling (2006) simularam a influência do coeficiente de atrito em ligações pilarfundação por meio de cálice, variando-se o valor de $0,60,0,45$ e 0,30 e constataram que o valor de 0,6 foi o que apresentou melhores resultados, quando comparados com resultados experimentais. Osanai et al. (1996) sugerem que os valores dos coeficientes de atrito tenham valores iguais a 0,5 e 1 , dependendo do comprimento de embutimento do pilar e do tipo de conformação das paredes do cálice e do pilar. Neste trabalho, seguindo as recomendações de Canha \& El Debs (2006) utilizou-se coeficiente de atrito igual a 0,6. É importante lembrar que esta análise numérica tem como objetivo apresentar tendência do comportamento da ligação pilar-fundação por meio de cálice embutido em blocos sobre duas estacas, com fim principal de analisar a relevância dos fatores analisados.

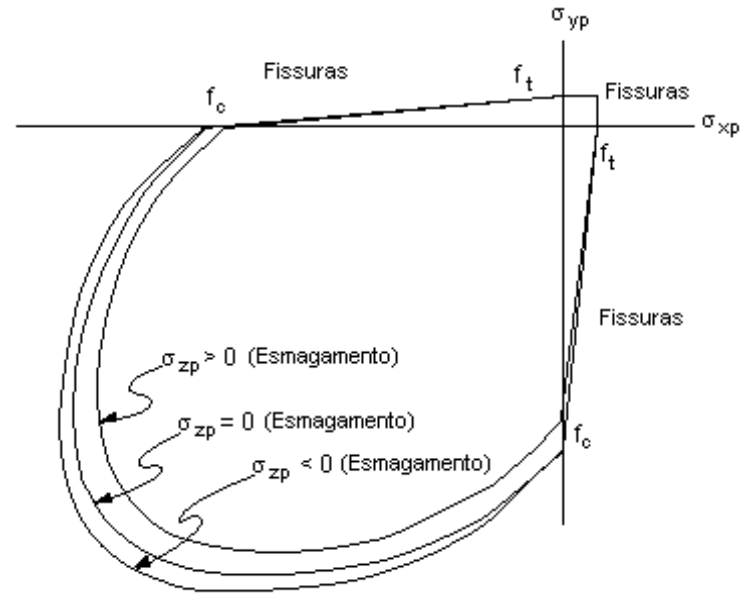

Figura 9: Superfície de ruptura, Concrete, Ansys ${ }^{\circledR}$ (2011).

Com relação à tensão de cisalhamento, $\tau_{\text {máx }}$ adotou-se o valor utilizado pelo programa de computador, $\left[\sigma_{y} /\left(3^{1 / 2}\right)\right]$, em que $\sigma_{y}$ é a resistência ao escoamento do critério de ruptura de Von Mises, do material adjacente à superfície de contato. Para $\sigma_{y}$ utilizou-se valores indicados por Canha (2004), sendo que essa tensão vale trinta por cento da resistência à compressão do concreto de menor resistência pertencente ao contato. Portanto, o valor de $\sigma_{y}$ adotado foi igual a 7,5 MPa, resultando 2,5 MPa para o valor de $\tau_{\text {máx} \cdot}$ 


\subsection{Análise comparativa}

Visando verificar se os modelos adotados para a análise numérica dos blocos sobre duas estacas mostram tendência de comportamento correta, fizeramse análises comparativas de ensaios experimentais e simulações de vários pesquisadores. Neste trabalho são apresentados os resultados das análises numéricas comparativas dos ensaios realizados por Mautoni (1972) e da simulação numérica desenvolvida por lyer \& Sam (1995). Em Delalibera (2006), pode-se observar os restantes das análises comparativas realizadas.

Na análise comparativa, também utilizaram-se os mesmos elementos finitos empregados nas análises dos blocos sobre duas estacas, ou seja, o Solid 65 discretizando o material concreto e o Link 8 modelando as barras de aço. Todas as propriedades mecânicas e geométricas adotadas na análise comparativa foram as mesmas dos ensaios experimentais. As condições de contorno empregadas nos modelos numéricos procuram representar as condições de contorno empregadas nos experimentos com maior grau de realidade possível, o mesmo acontecendo com o carregamento.

A primeira análise comparativa trata-se do bloco B1-A ensaiado por Mautoni (1972). O bloco teve ruína por cisalhamento com força última igual a $800 \mathrm{kN}$. A primeira fissura surgiu com aproximadamente trinta por cento da força última, cerca de $240 \mathrm{kN}$. O bloco tinha altura de vinte e cinco centímetros, o pilar era quadrado com área igual a $225 \mathrm{~cm}^{2}$ e as estacas tinham seções transversais iguais a $10 \mathrm{~cm} \times 15 \mathrm{~cm}$. O concreto apresentou resistência à compressão igual a 32,30 MPa e as barras de aço do tirante apresentaram resistência ao escoamento igual a $720 \mathrm{MPa}$. Como não existiam informações sobre o módulo de elasticidade e sobre os coeficientes de Poisson do aço e concreto, adotaram-se as recomendações da ABNT NBR 6118:2007.

Aplicou-se no modelo numérico trezentos incrementos de força, sendo que, para cada incremento o valor da força aplicada era de 2,67 kN.

A Figura 10 mostra a configuração final obtida no experimento e na simulação do bloco B1-A.

O valor da força que originou a primeira fissura no modelo numérico foi de 312,33 kN. Ocorreu diferença de $23,15 \%$ com relação ao valor da força que originou a primeira fissura no modelo experimental. Isso ocorreu, pois, no modelo experimental, a força que provocou a primeira fissura foi determinada em função de observação visual, ou seja, a primeira fissura visível ao olho humano. Com relação à força última, o modelo numérico, apresentou força última de 799,98 kN, praticamente, não ocorrendo diferença com o valor obtido experimentalmente.

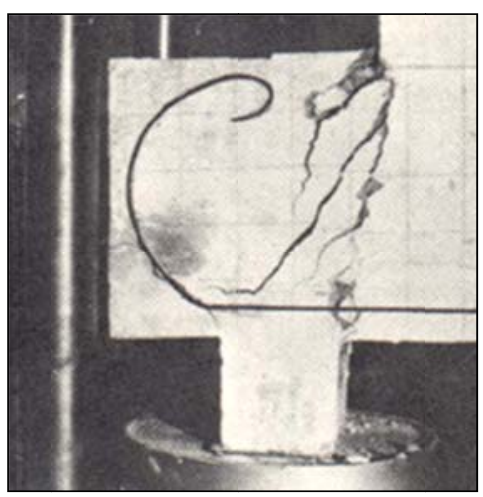

Experimental

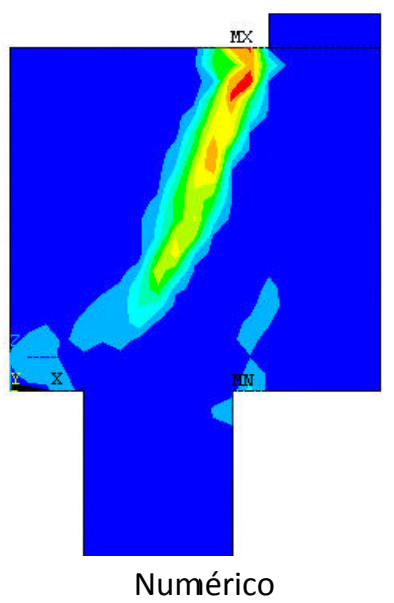

Figura 10: Configuração final do bloco B1-A, ensaiado por Mautoni (1972).

A segunda análise comparativa refere-se aos blocos simulados numericamente por lyer \& Sam (1995). Foram simulados os blocos com arranjo de armadura distribuída em malha e sobre as estacas. Os blocos tinham altura de vinte e dois centímetros e cinco milímetros, e eram compostos por quatros estacas com seção transversal quadrada de $10 \mathrm{~cm} \times 10 \mathrm{~cm}$. Os pilares também tinham seção quadrada com 14,14 cm x 14,14 $\mathrm{cm}$ de lado. A resistência característica do concreto era igual a $19 \mathrm{MPa}$ e a resistência característica ao escoamento das barras de aço igual a $300 \mathrm{MPa}$. O coeficiente de Poisson adotado para aço e concreto foi 0,3 e 0,2, respectivamente. Nas simulações numéricas adotaram-se 345 incrementos de força. As forças últimas obtidas nas análises desenvolvidas por lyer \& Sam (1995) foram de: $600 \mathrm{kN}$, para armadura em malha e $560 \mathrm{kN}$, para armadura sobre as estacas. Na simulação numérica desenvolvida neste texto, as forças encontradas foram de: $582,17 \mathrm{kN}$ para os blocos com arranjo de armadura distribuída em malha, e 594,59 kN para os blocos com arranjo de armadura distribuída sobre as estacas. A Figura 11 apresenta as correlações entre os resultados obtidos.

quantitativa, mas a variável dependente 


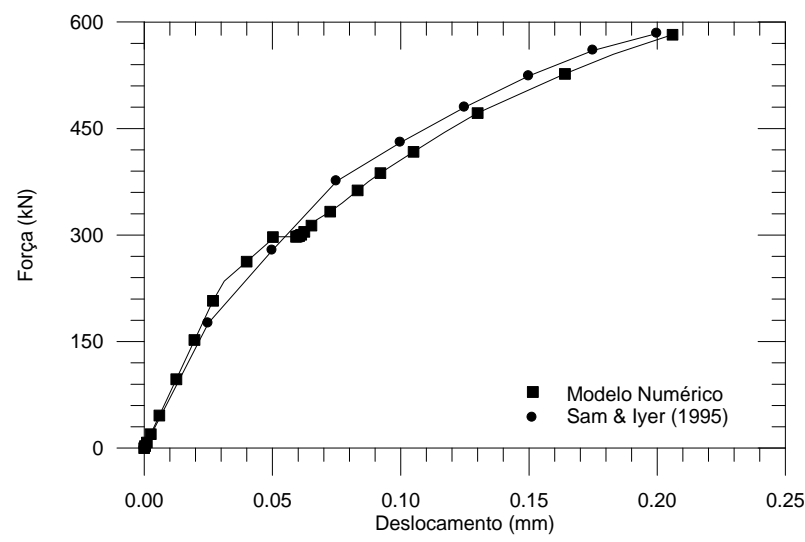

a. Armadura distribuída em malha.

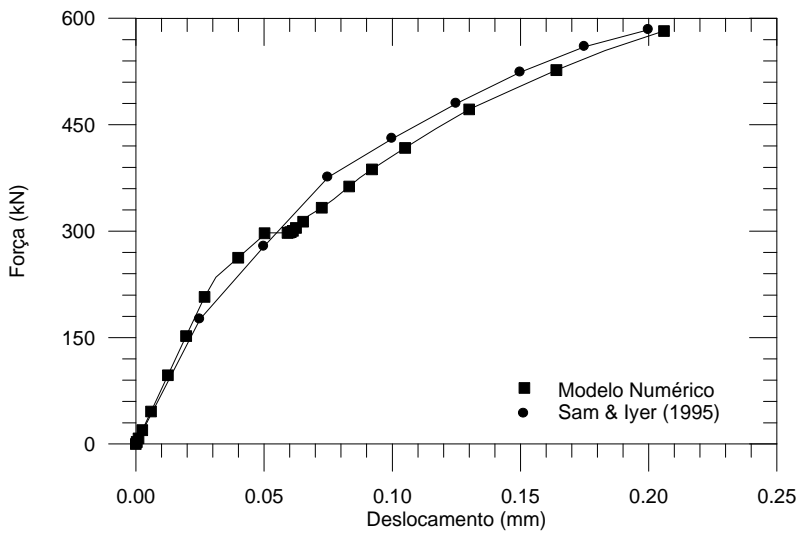

b. Armadura distribuída sobre as estacas

Figura 11: Análise comparativa, Sam \& Iyer (1995).

Observa-se por meio da Figura 11, que existe ótima correlação entre os resultados, indicando que o modelo adotado na análise numérica é coerente.

\section{ANÁLISE DE VARIÂNCIA}

A análise de variância (ANOVA) é um teste estatístico amplamente difundido, que visa fundamentalmente, verificar se existe diferença significativa entre as médias, e se os fatores exercem influência em alguma variável dependente. Os fatores propostos podem ser de origem qualitativa ou necessariamente deverá ser contínua.

A principal aplicação da ANOVA é a comparação de médias oriundas de grupos diferentes, também chamados tratamentos. Existem dois tipos de problemas a serem resolvidos por meio da Anova: fatores fixos ou fatores aleatórios. A aleatoriedade determina a questão do problema.

$\mathrm{Na}$ grande maioria dos casos trata-se de fatores fixos, afinal o segundo tipo de problema (aleatório) somente surgirá quando ocorrer um estudo envolvendo uma escolha aleatória de fatores.

A análise de variância é amplamente utilizada em diversas áreas, por exemplo: na indústria, com objetivo de otimizar a linha de produção; na medicina, com o objetivo de identificar quais fatores são importantes no tratamento de uma determinada patologia. Na Engenharia Civil, sua utilização ainda é restrita, porém, já existem trabalhos desenvolvidos utilizando a técnica, como por exemplo: Delalibera (2002), Lima Júnior (2003), Delalibera \& Giongo (2004), Delalibera (2006) e Buttler (2007).

$\mathrm{Na}$ análise de variância desenvolvida neste trabalho, utilizaram-se fatores fixos, escolhendo três variáveis de estudo: o comprimento de embutimento do pilar no cálice $\left(\ell_{\mathrm{emb}}\right)$; a espessura da "laje" de fundo do bloco $\left(h_{s}\right)$; e a conformação das paredes do cálice embutido e do pilar pré-moldado. As variáveis escolhidas totalizaram dezoito casos de combinações. Os modelos foram divididos em dois grupos (paredes lisas - $L$ e paredes rugosas $-R$ ).

\subsection{Formulação da análise de variância}

Sejam A e B os fatores principais fixos da análise de variância, a, b e c, as variações desses fatores e $\mathrm{n}$ o número de réplicas. Em geral existirá abc...n combinações possíveis.

Se todos os fatores do experimento forem fixados, pode-se facilmente formular o problema, obtendo resultados que indicam quais dos fatores analisados são importantes como também suas combinações.

O Quadro 2 apresenta uma analise de variância com dois fatores.

\begin{tabular}{|c|c|c|c|c|}
\hline Fatores & $\begin{array}{c}\text { Soma dos } \\
\text { quadrados }\end{array}$ & Graus de Liberdade & Média dos Quadrados & $F_{0}$ \\
\hline A & SSA & $a-1$ & $M S A=S S A /(a-1)$ & $F_{0}=\frac{M_{A}}{M S_{E}}$ \\
\hline B & SSB & $b-1$ & $M S B=S S b /(b-1)$ & $F_{0}=\frac{M_{B}}{M_{E}}$ \\
\hline A x B & SSAB & $(a-1)(b-1)$ & $M S A B=S S A B /[(a-1)(b-1)]$ & $F_{0}=\frac{M_{A B}}{M S_{E}}$ \\
\hline Erro & SSE & $a b c(n-1)$ & $M S E=S S E /[a b c(n-1)]$ & \\
\hline Total & SST & $a b c n-1$ & & \\
\hline
\end{tabular}


Para verificar a relevância de um determinado fator principal fixo ou combinações entre os fatores principais, faz-se a relação entre a média dos quadrados de cada fator principal ou combinação dos fatores principais pela média dos quadrados dos erros. A divisão entre a média dos quadrados de cada fator principal ou combinação dos fatores principais pela média dos erros é chamada de $F_{0}$.

O número de graus de liberdade de cada fator principal é igual ao número de variações de cada fator menos a unidade. O número de graus de liberdade dos fatores principais combinados é o produto entre os fatores principais que foram combinados.

A soma total dos quadrados é calculada por meio da Equação 1.

$$
S S_{T}=\sum_{i=1}^{a} \sum_{j=1}^{b} \sum_{k=1}^{c} \sum_{l=1}^{n} y_{i j k l}^{2}-\frac{y^{2} \ldots .}{a b c n}
$$

A soma dos quadrados da combinação $A \times B \times$ C é expressa por meio da Equação 2. A soma dos quadrados do erro é definida pela Equação 3.

$$
S S_{A B}=\sum_{i=1}^{a} \sum_{j=1}^{b} \frac{y_{i j . .}^{2}}{c n}-\frac{y_{\ldots . .}^{2}}{a b c n}-S S_{A}-S S_{B}
$$

$$
S S_{E}=S S_{T}-\sum_{i=1}^{a} \sum_{j=1 k=1}^{b} \sum_{i j k}^{c} \frac{y_{. i j k .}^{2}}{n}-\frac{y^{2} \ldots .}{a b c n}
$$

Para verificação da relevância de uma determinada variável principal fixa ou combinada, aplica-se o teste F. Por meio de valores tabelados de

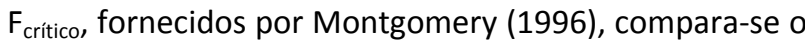
valor calculado de $F_{0}$ com o valor de $F_{\text {crítico. }}$ Se o valor calculado de $F_{0}$ for maior que o valor tabelado de $F_{\text {crítico }}$ significa que esse fator é relevante, caso contrário, implica que o fator não possui importância significativa. Os valores de $F_{\text {crítico }}$ são função do número de graus de liberdade de cada variável e do número de graus de liberdade total.

\section{RESULTADOS OBTIDOS}

5.1. Análise dos blocos sobre duas estacas com conformação lisa na interface cálice-bloco.

Foram analisados nove blocos solicitados apenas por ação de força de normal de compressão, com variações no comprimento de embutimento do pilar $\left(\ell_{\text {emb }}\right)$ e na espessura da "laje" de fundo do bloco $\left(h_{s}\right)$. A variação dos fatores analisados modificou de modo significativo a distribuição das tensões principais de compressão e o panorama de fissura no último

\begin{tabular}{|c|c|c|c|c|c|c|c|c|c|}
\hline \multirow{2}{*}{ Blocos } & \multirow{2}{*}{$\begin{array}{l}\text { Seção dos } \\
\text { pilares } \\
\text { (cm) }\end{array}$} & \multirow{2}{*}{$\begin{array}{c}\text { Seção das } \\
\text { estacas } \\
\text { (cm) }\end{array}$} & \multirow{2}{*}{$\begin{array}{c}h_{\mathrm{s}} \\
(\mathrm{cm})\end{array}$} & \multirow{2}{*}{$\begin{array}{l}\ell_{\text {emb }} \\
(\mathrm{cm})\end{array}$} & \multirow{2}{*}{$\begin{array}{c}\theta \\
\text { (graus) }\end{array}$} & \multirow{2}{*}{$\begin{array}{c}\mathrm{h} \\
(\mathrm{cm})\end{array}$} & \multicolumn{2}{|c|}{$\begin{array}{c}F_{u} \\
(k N)\end{array}$} & \multirow{2}{*}{$F_{\text {blévot }} / F_{\text {num }}$} \\
\hline & & & & & & & Blévot & Num. & \\
\hline Lee80hs30N & $20 \times 20$ & $20 \times 20$ & 30 & 80 & 54,0 & 120 & 3663 & 2952 & 1,24 \\
\hline Lee80hs20N & $20 \times 20$ & $25 \times 25$ & 20 & 80 & 51,3 & 110 & 3415 & 2860 & 1,19 \\
\hline Lee80hs10N & $20 \times 20$ & $30 \times 30$ & 10 & 80 & 48,4 & 100 & 3128 & 2840 & 1,10 \\
\hline Lee60hs30N & $20 \times 30$ & $20 \times 20$ & 30 & 60 & 48,4 & 100 & 3128 & 2860 & 1,09 \\
\hline Lee60hs20N & $20 \times 30$ & $25 \times 25$ & 20 & 60 & 45,0 & 100 & 2800 & 2528 & 1,10 \\
\hline Lee60hs10N & $20 \times 30$ & $30 \times 30$ & 10 & 60 & 41,2 & 80 & 2428 & 1556 & 1,56 \\
\hline Lee50hs30N & $20 \times 40$ & $20 \times 20$ & 30 & 50 & 45,0 & 90 & 2800 & 2585 & 1,08 \\
\hline Lee50hs20N & $20 \times 40$ & $25 \times 25$ & 20 & 50 & 41,2 & 80 & 2428 & 1406 & 1,72 \\
\hline Lee50hs10N & $20 \times 40$ & $30 \times 30$ & 10 & 50 & 36,9 & 70 & 2016 & 578 & 3,48 \\
\hline
\end{tabular}
incremento de força aplicado aos modelos. O Quadro 3 apresenta resultados das análises numéricas realizadas.

Nota: Num., valor obtido por meio da simulação numérica; Blévot, valor calculado por meio dos critérios de Blévot \& Fremy (1967); $F_{u}$, força última. 
Por meio dos valores mostrados no Quadro 4, percebe-se que os modelos numéricos apresentaram boa correlação com os valores analíticos, a menos dos modelos Lle60hs10N, Lle50hs20N e Lle50hs10N. Nesses modelos, a espessura da "laje" de fundo como também o comprimento de embutimento do pilar $\left(\ell_{\mathrm{emb}}\right)$, provocaram mudanças no comportamento estrutural do conjunto (pilar- material de preenchimento - bloco estacas). Os possíveis modos de ruína para estes modelos podem estar relacionados com punção da "laje" de fundo, pois a espessura da laje é pequena e o comprimento de embutimento do pilar $\left(\ell_{\mathrm{emb}}\right)$, para pilares com paredes lisas, insuficiente para transmitir às tensões de compressão ao longo da altura do cálice.

Observa-se por meio da Figura 12, que os blocos apresentam intensa fissuração em virtude da existência de tensões de tração, ocorrido em função do fendilhamento das escoras (tensões de tração perpendiculares às tensões de compressão nas escoras). O restante do panorama de fissuração pode ser observado em Delalibera (2012).

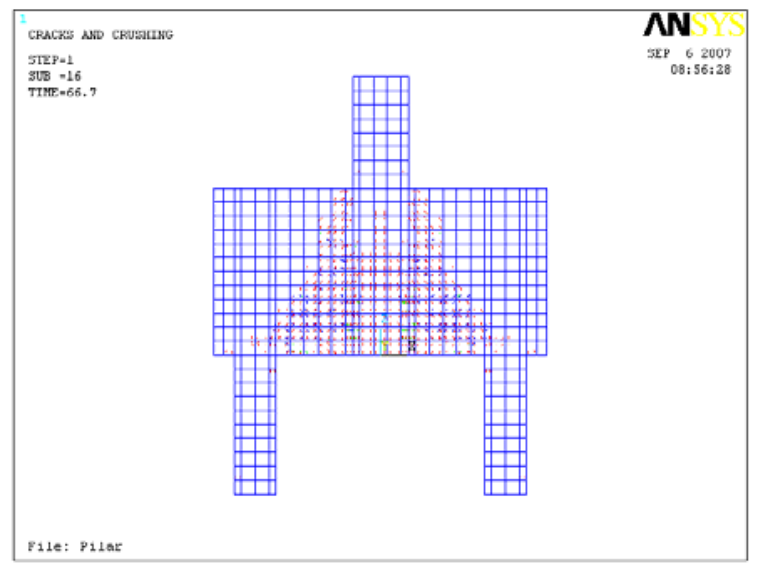

a. blocos $\mathrm{Re}_{\mathrm{e}} 80 \mathrm{~h}_{\mathrm{s}} 30 \mathrm{~N}$.

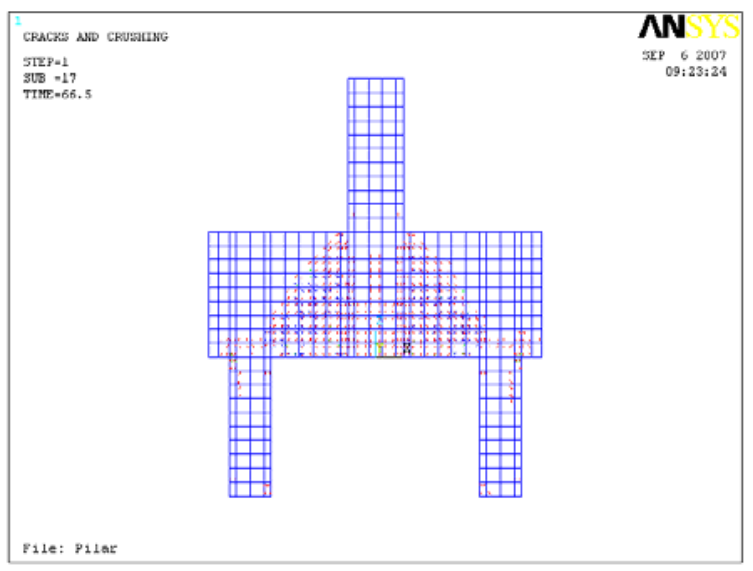

b. blocos $R \ell_{e} 50 h_{s} 30 \mathrm{~N}$.

Figura 12: Panorama de fissuração.

Por meio da Figura 13 observa-se a distribuição das tensões principais de compressão no interior do bloco. Constata-se que a rigidez do bloco é proporcional à sua capacidade resistente. As outras informações a respeito das tensões principais de compressão podem ser observadas em Delalibera (2012). A Figura 14 apresenta as curvas força aplicada no pilar vs. deslocamento no meio do vão do bloco.

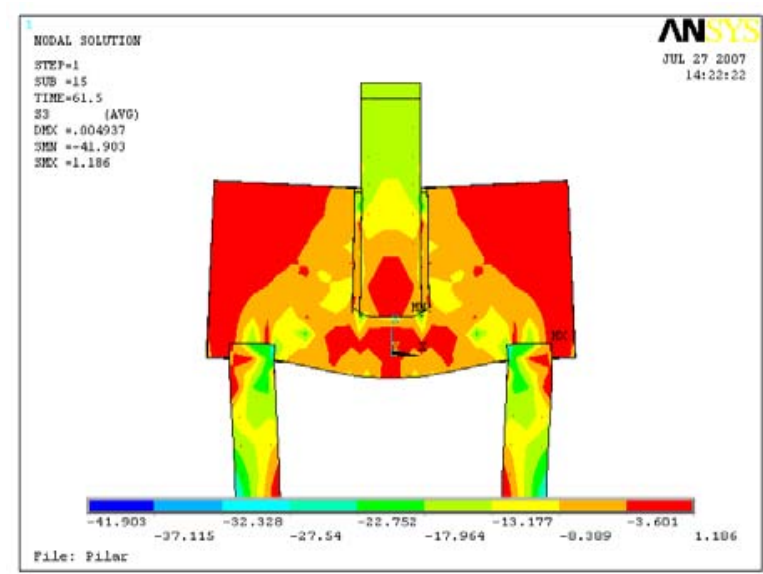

a. bloco $\mathrm{Le}_{\mathrm{e}} 80 \mathrm{~h}_{\mathrm{s}} 30 \mathrm{~N}$

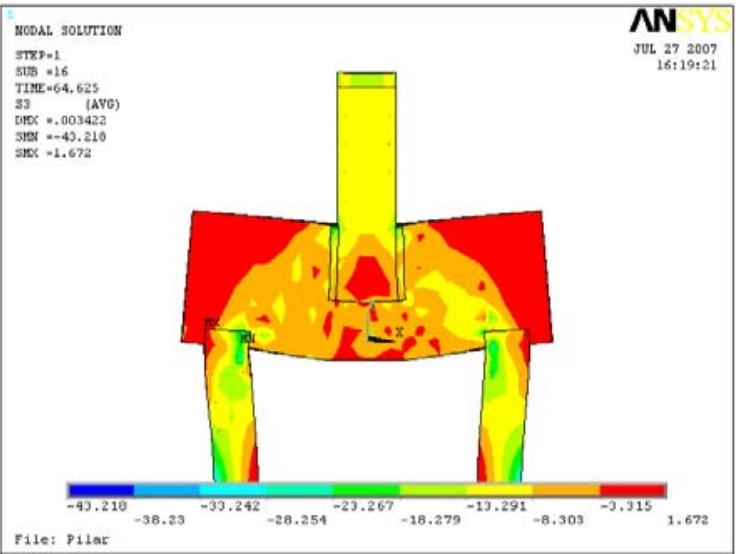

b. bloco $\mathrm{Le}_{\mathrm{e}} 50 \mathrm{~h}_{\mathrm{s}} 30 \mathrm{~N}$

Figura 13: Tensões principais de compressão.

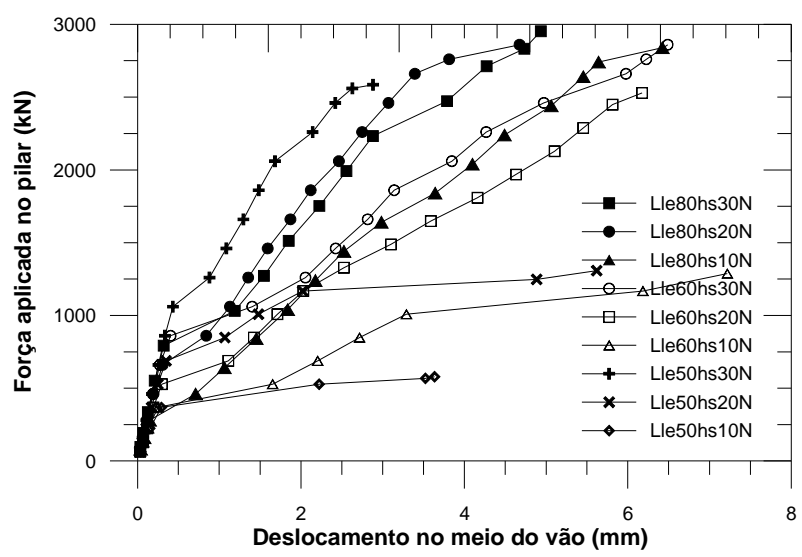

Figura 14: Curva força normal aplicada no pilar vs. deslocamento no meio do vão do bloco, interface lisa.

Por meio da análise numérica, observou-se que existem diferenças significativas nas áreas das bielas de compressão junto à estaca, quando 
comparadas com as áreas das bielas calculadas utilizando os critérios de Blévot \& Frémy (1967). Observou-se que as áreas das estacas efetivamente comprimidas pelas bielas de compressão nos modelos numéricos possuem áreas aproximadamente iguais à metade da área calculada com os critérios de Blévot \& Frémy (1967). Faz-se necessário, portanto, estabelecer critérios rigorosos para a determinação da forma geométrica das bielas de compressão.

O Quadro 4 mostra os resultados da análise de variância dos blocos analisados numericamente, com conformação lisa da interface bloco-cálice, submetidos à ação de força normal centrada de compressão. A significância utilizada na análise de variância foi de 99 .

Por meio do Quadro 4, conclui-se que para os blocos submetidos à forças verticais de compressão e com conformações lisas das paredes do cálice e do pilar, o fator $\ell_{\text {emb }}$ tem importância relevante em relação à capacidade portante, seguido do fator $h_{s}$.

Estes resultados mostram que para blocos com cálice embutido com conformação lisa das paredes do cálice e do pilar, a capacidade portante do bloco é influenciada principalmente pelo comprimento de embutimento do pilar no cálice. A espessura da "laje" de fundo é fator relevante, porém de menor influência.

\subsection{Análise dos blocos sobre duas estacas com conformação rugosa na interface cálice-bloco.}

O Quadro 5 apresenta resultados das análises numéricas realizadas e a Figura 15 apresenta as curvas força aplicada no pilar vs. deslocamento no meio do vão do bloco.

Quadro 4 : Análise de variância, blocos com conformação lisa, força normal de compressão.

\begin{tabular}{|c|c|c|c|c|c|}
\hline Fator & $\begin{array}{c}\text { Soma dos } \\
\text { quadrados }\end{array}$ & $\begin{array}{c}\text { Graus de } \\
\text { liberdade }\end{array}$ & $\begin{array}{c}\text { Média dos } \\
\text { quadrados }\end{array}$ & Fator F0 & $\begin{array}{c}\text { Significância } \\
\text { F0,01 }\end{array}$ \\
\hline $\boldsymbol{l}_{\mathrm{emb}}$ & 2803198 & 2 & 1401599 & 28,39 & 8,65 \\
\hline $\mathbf{h}_{\mathrm{s}}$ & 1955438 & 2 & 977718,8 & 19,80 & 8,65 \\
\hline $\boldsymbol{\ell}_{\mathrm{emb}} \mathbf{x} \mathbf{h}_{\mathrm{s}}$ & 856603 & 4 & 214150,8 & 4,34 & 7,01 \\
\hline Erro & 148128 & 3 & 49375,9 & - & - \\
\hline Total & 5763366 & 8 & 720420,8 & - & - \\
\hline
\end{tabular}

Nota: $\ell_{e m b} \times h_{s}$, acoplamento entre o comprimento de embutimento do pilar e a espessura da "laje" de fundo.

Quadro 5: Resultados obtidos por meio da análise numérica para os blocos com interface rugosa.

\begin{tabular}{|c|c|c|c|c|c|c|c|c|c|}
\hline \multirow{2}{*}{ Blocos } & \multirow{2}{*}{$\begin{array}{c}\text { Seção do } \\
\text { pilar } \\
\text { (cm) }\end{array}$} & \multirow{2}{*}{$\begin{array}{c}\text { Seção da } \\
\text { estacas } \\
(\mathrm{cm})\end{array}$} & \multirow{2}{*}{$\begin{array}{c}h_{\mathrm{s}} \\
(\mathrm{cm})\end{array}$} & \multirow{2}{*}{$\begin{array}{l}e_{\text {emb }} \\
(\mathrm{cm})\end{array}$} & \multirow{2}{*}{$\begin{array}{c}\theta \\
\text { (graus) }\end{array}$} & \multirow{2}{*}{$\begin{array}{c}\mathrm{h} \\
(\mathrm{cm})\end{array}$} & \multicolumn{2}{|c|}{$\begin{array}{c}F_{u} \\
(k N)\end{array}$} & \multirow{2}{*}{$F_{\text {blévot }} / F_{\text {num }}$} \\
\hline & & & & & & & Blévot & Num. & \\
\hline Rle80hs30N & $20 \times 20$ & $20 \times 20$ & 30 & 80 & 54,0 & 120 & 3663 & 3202 & 1,14 \\
\hline Rle80hs20N & $20 \times 20$ & $25 \times 25$ & 20 & 80 & 51,3 & 110 & 3415 & 3260 & 1,05 \\
\hline Rle80hs10N & $20 \times 20$ & $30 \times 30$ & 10 & 80 & 48,4 & 100 & 3128 & 2860 & 1,09 \\
\hline Ree60hs30N & $20 \times 30$ & $20 \times 20$ & 30 & 60 & 48,4 & 100 & 3128 & 2960 & 1,06 \\
\hline Rle60hs20N & $20 \times 30$ & $25 \times 25$ & 20 & 60 & 45,0 & 100 & 2800 & 2928 & 0,96 \\
\hline Rle60hs10N & $20 \times 30$ & $30 \times 30$ & 10 & 60 & 41,2 & 80 & 2428 & 1468 & 1,65 \\
\hline Ree50hs30N & $20 \times 40$ & $20 \times 20$ & 30 & 50 & 45,0 & 90 & 2800 & 2660 & 1,05 \\
\hline Rle50hs20N & $20 \times 40$ & $25 \times 25$ & 20 & 50 & 41,2 & 80 & 2428 & 1288 & 1,89 \\
\hline Rle50hs10N & $20 \times 40$ & $30 \times 30$ & 10 & 50 & 36,9 & 70 & 2016 & 2214 & 0,91 \\
\hline
\end{tabular}

Nota: Num., valor obtido por meio da simulação numérica; Blévot, valor calculado por meio dos critérios de Blévot \& Fremy (1967); $F_{u}$, força última. 


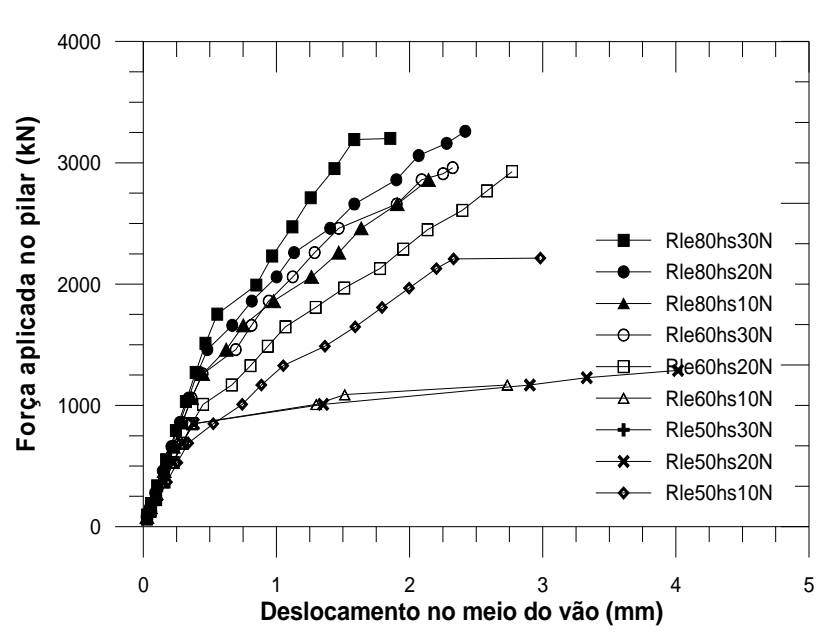

Figura 15: Curva força normal aplicada no pilar vs. deslocamento no meio do vão do bloco, interface rugosa.

Observa-se por meio do Quadro 5 que os valores numéricos apresentam boa correlação com os valores analíticos a menos dos modelos $R \ell_{e} 60 h_{s} 10 \mathrm{~N}$ e $\mathrm{Re}_{\mathrm{e}} 50 \mathrm{~h}_{\mathrm{s}} 20 \mathrm{~N}$.

Partindo da premissa que outros pesquisadores que analisaram cálices com chave de cisalhamento e observaram comportamento monolítico, pode-se afirmar que ocorreram problemas de convergência numérica com os modelos $R_{e} 60 h_{s} 10 \mathrm{~N}$ e $\mathrm{Re}_{\mathrm{e}} 50 \mathrm{~h}_{\mathrm{s}} 20 \mathrm{~N}$.

Observa-se também, por meio da Figura 15, que os modelos com menor rigidez apresentam maior deslocamento.

A Figura 16 mostra as tensões principais de compressão e a Figura 17 apresenta o panorama de fissuras do dos blocos analisados numericamente com interface rugosa.

Observando a Figura 16 nota-se que as cabeças das estacas não são solicitadas uniformemente, portanto, é necessário utilizar método de verificação das regiões nodais inferior que considerem flexocompressão.

Resultados obtidos por Delalibera (2006) confirmam os comportamentos dos modelos obtidos por meio de simulações numéricas. Os restantes das tensões principais de compressão e do panorama de fissuração podem ser observados em Delalibera (2012).

Por meio da Figura 17 observa-se que as fissuras se desenvolvem na região delimitada pelas diagonais comprimidas.

Outro resultado muito interessante que condiz com afirmações de outros pesquisadores pode ser observado por meio dos valores do Quadro 6.
Como a ligação com chave de cisalhamento, confere à ligação pilar-fundação comportamento monolítico, é de esperar que a ruína dos blocos esteja associada com outros fatores. Isso foi constatado, pois nota-se que os fatores previamente escolhidos para esta análise não foram relevantes, ou seja, não apresentaram valores significantes. O Quadro 6 apresenta os resultados da análise de variância dos blocos com conformidade rugosa das paredes do cálice e do bloco.

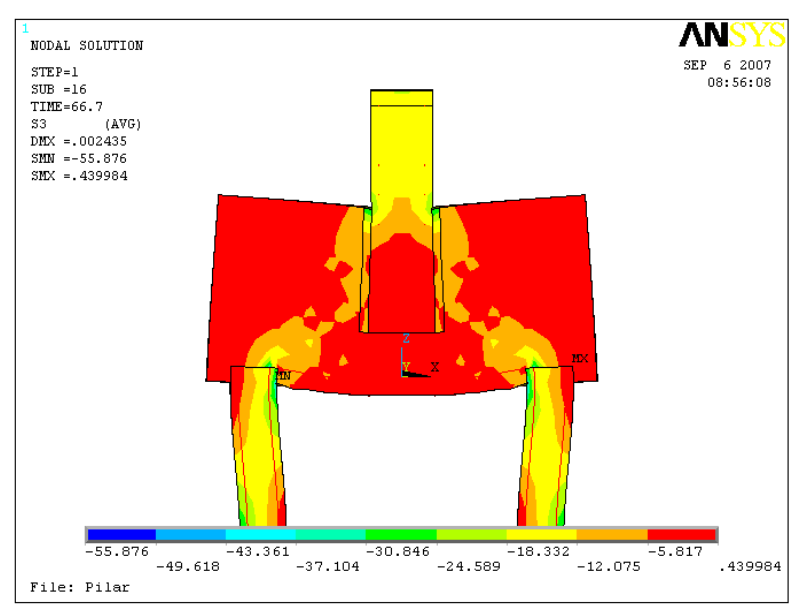

a. bloco $\mathrm{Re}_{\mathrm{e}} 80 \mathrm{~h}_{\mathrm{s}} 30 \mathrm{~N}$

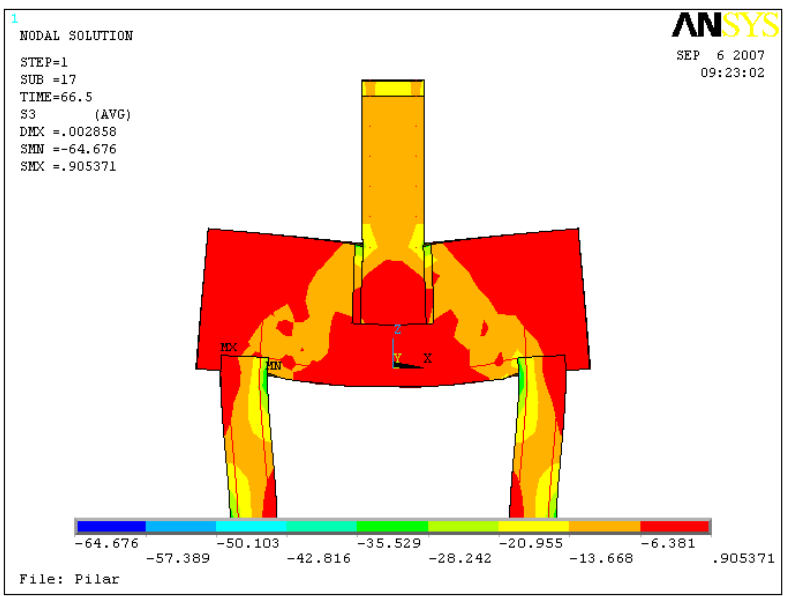

b. bloco Re $50 h_{s} 30 \mathrm{~N}$

Figura 16: Tensões principais de compressão. 


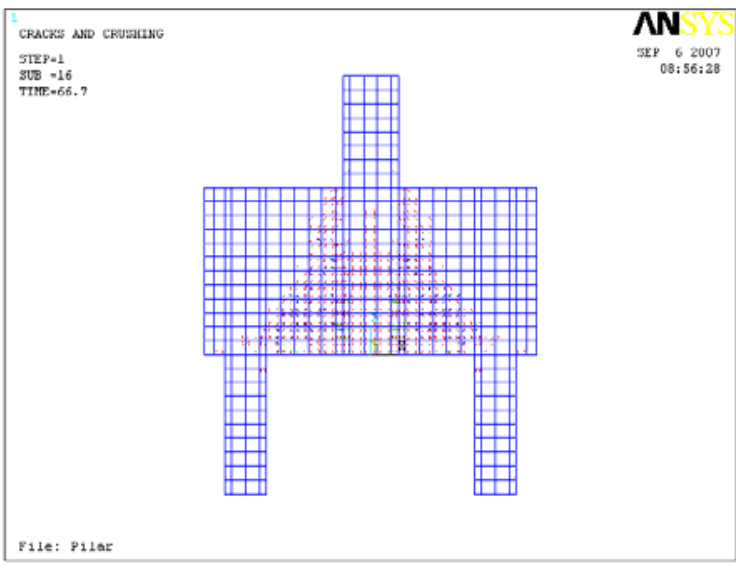

a. blocos $\mathrm{Rl}_{\mathrm{e}} 80 \mathrm{~h}_{\mathrm{s}} 30 \mathrm{~N}$.

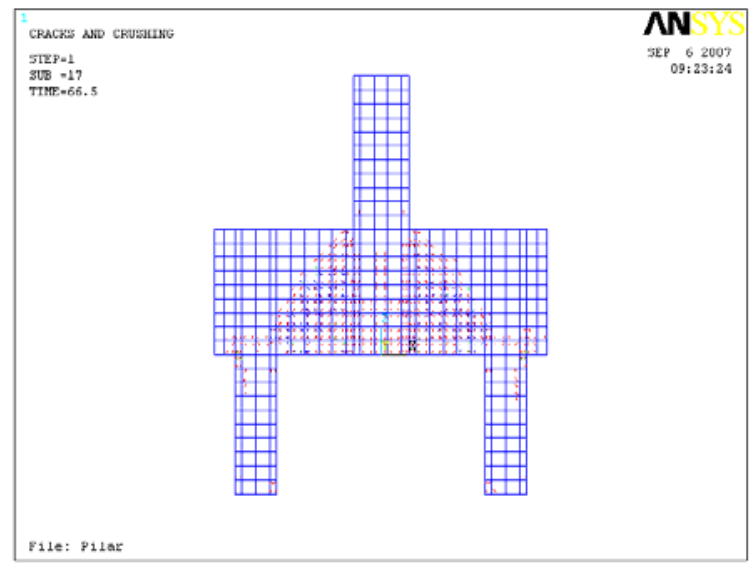

b. blocos $\mathrm{Re}_{\mathrm{e}} 50 \mathrm{~h}_{\mathrm{s}} 30 \mathrm{~N}$.

Figura 17: Panorama de fissuração.

Quadro 6 : Análise de variância, blocos com conformação rugosa, força normal de compressão.

\begin{tabular}{|c|c|c|c|c|c|}
\hline Fator & $\begin{array}{c}\text { Soma dos } \\
\text { quadrados }\end{array}$ & $\begin{array}{c}\text { Graus de } \\
\text { liberdade }\end{array}$ & $\begin{array}{c}\text { Média dos } \\
\text { quadrados }\end{array}$ & Fator F0 & $\begin{array}{c}\text { Significância } \\
\text { F0,01 }\end{array}$ \\
\hline $\boldsymbol{l}_{\mathrm{emb}}$ & 1697377 & 2 & 848688 & 1,58 & 8,65 \\
\hline $\mathrm{h}_{\mathrm{s}}$ & 875380 & 2 & 437915 & 0,82 & 8,65 \\
\hline $\boldsymbol{l}_{\mathrm{emb}} \times \mathrm{h}_{\mathrm{s}}$ & 43964 & 4 & 10991 & 0,02 & 7,01 \\
\hline Erro & 1606137 & 3 & 535379 & - & - \\
\hline Total & 4223308 & 8 & 527913 & - & - \\
\hline
\end{tabular}

Nota: $\ell_{\text {emb }} \times h_{s}$, acoplamento entre o comprimento de embutimento do pilar e a espessura da "laje" de fundo.

\subsection{Tensões nas barras de aço}

Analisando a Figura 18 percebe-se que as barras de aço da armadura dos modelos apresentaram valores consistentes e em alguns casos, ocorreu escoamento. Observa-se que no modelo $\mathrm{Ll}_{\mathrm{e}} 60 \mathrm{~h}_{\mathrm{s}} 2 \mathrm{MM}$, ocorreu escoamento das barras de aço do pilar e em algumas barras de aço das estacas, ocorreram tensões de tração. Esses resultados são coerentes, pois são satisfatórios em função das ações externas aplicadas.

Os resultados apresentados na Figura 18 corroboram com os resultados apresentados por Adebar et al. (1990), Miguel (2000) e Delalibera (2006). Pois, a tensão nas barras da armadura principal de tração não é constante, tendo valores nulos (ou até negativo) na ponta dos tirantes, e valores máximos no meio de vão. Observa-se também, que as barras de aço que compõem a armadura das estacas apresentam tensões com valores diferentes, o que indica flexo-compressão nas estacas.

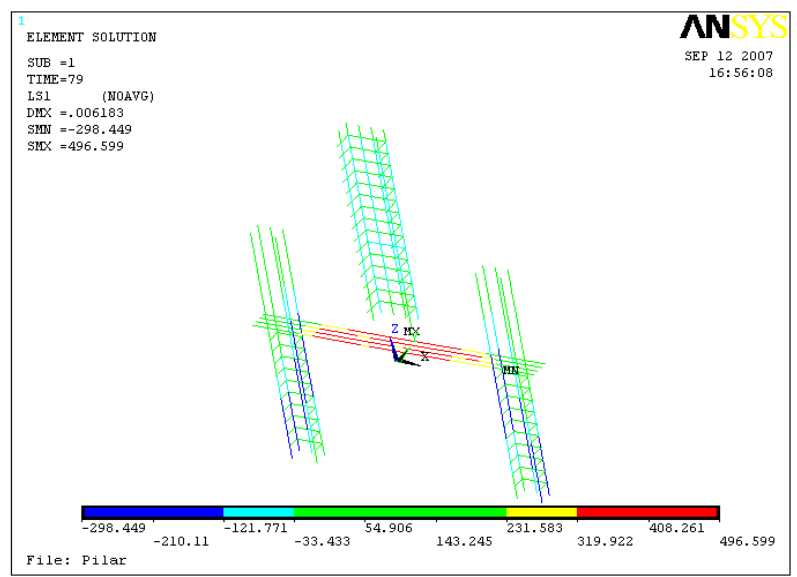

Figura 18: Tensões nas barras de aço, Lle60hs20N, tensões expressas em MPa.

\section{CONCLUSÃO}

As simulações numéricas se mostraram coerente e apontaram tendência do comportamento 
estrutural de blocos sobre duas estacas com cálice embutido, com conformação das paredes do cálice e do pilar lisas e rugosas.

Observaram-se para os blocos com interface lisa entre as paredes do cálice e do pilar, os seguintes fatores: comprimento de embutimento do pilar $\left(\ell_{e m b}\right)$ e espessura da laje de fundo $\left(h_{s}\right)$, tem importância relevante na capacidade portante dos modelos. Pois, os modelos analisados numericamente com maiores comprimentos de embutimento do pilar e maiores espessuras da "laje" de fundo, apresentaram maiores capacidade portantes. Além disso, ficou evidente que nas situações em que se tinha comprimento de embutimento do pilar diminuído, pequena espessura da "laje" de fundo, e somente ação de força normal, a possível ruína ocorreria por punção do bloco na região de contato entre a base do pilar e a base do bloco.

Para os modelos simulados com interface rugosa entre as paredes do cálice e do pilar (chave de cisalhamento), os fatores analisados $\left(\ell_{e m b}\right.$ e $\left.h_{s}\right)$ não foram relevantes na determinação da capacidade portante dos blocos. Esses resultados são interessantes, pois é possível projetar blocos sobre estacas com cálice embutidos e chave de cisalhamento, com modelos de bielas e tirantes, preocupando-se apenas com a punção da "laje" de fundo do bloco, durante a fase de montagem (ou seja, antes da aplicação do material de preenchimento).

Observou-se também que a rigidez do bloco influencia na capacidade portante do mesmo. Pode-se se afirmar isso, em função dos resultados obtidos, pois os modelos com maiores alturas foram os que apresentaram maior capacidade resistente.

Observou-se também, e isso já era esperado, que os modelos analisados numericamente com interface lisa, apresentaram menor capacidade portante com relação aos modelos analisados numericamente com interface rugosa.

\section{AGRADECIMENTOS}

Ao CNPq - Conselho Nacional de Desenvolvimento Científico e Tecnológico e à FAPESP - Fundação de Amparo à Pesquisa do Estado de São Paulo pelo apoio financeiro para fazer a pesquisa que permitiu escrever este artigo.

\section{REFERÊNCIAS BIBLIOGRÁFICAS}

ASSOCIAÇÃO BRASILEIRA DE NORMA TÉCNICAS, ABNT NBR 6118:2003 Projeto de estruturas de concreto. Rio de Janeiro, 2007.
ABNT NBR 9062:2005 Projeto e execução de estruturas de concreto pré-moldado. Rio de Janeiro, 2006.

ABEBAR, P.. One-way shear strength of large footings. Can. J. Civ. Eng. 27: 553-562, 2000.

ANSYS User's Manual. Theory Manual, ANSYS revision 5.5, 2011.

BLÉVOT, J.; FRÉMY, R.. Semelles sur piex. Analles d'Institut Techique du Bâtiment et des Travaux Publics, Paris, v. 20, n. 230, p. 223-295, fev, 1967.

BUTTLER, A. M.. Avaliação da incorporação de agregados reciclados de concreto na produção de blocos de concreto e no seu emprego na alvenaria estrutural. Tese (Doutorado). Escola de Engenharia de São Carlos, Universidade de São Paulo, São Carlos, 2007.

CANHA, R. M. F.; EL DEBS, M. K.. Proposta de modelo de prometo para a ligação pilar-fundação por meio de cálice em estruturas de concreto pré-moldado. Revista Ibracon de Estruturas. Vol. 2, no. 2, p. 137-166, junho, 2006.

DELALIBERA, R. G.. Análise teórica e experimental de vigas de concreto armado com armadura de confinamento. Dissertação (Mestrado). Escola de Engenharia de São Carlos, Universidade de São Paulo, São Carlos, 2002.

DELALIBERA, R. G.; GIONGO, J. S.. Simulação numérica nãolinear de blocos de concreto armado. XXXI Jornadas SulAmericanas de Engenharia Estrutural. CDROM, Mendonza, Argentina, 2004.

DELALIBERA, R. G.. Análise teórica e experimental de blocos de concreto armado sobre duas estacas submetidos a ação de força centrada e excêntrica. Tese (doutorado) - Escola de Engenharia de São Carlos, Universidade de São Paulo, São Carlos, 2006.

DELALIBERA, R. G.. Análise numérica de blocos sobre duas estacas, com cálice embutido, submetido à ação de força normal e excêntrica. Relatório científico - Universidade Federal de Goiás / CNPq - Conselho Nacional de desenvolvimento científico e tecnológico, 2012.

EBELING, E. B. (2006). Análise da base de pilares prémoldados na ligação com cálice de fundação. Dissertação (Mestrado), Escola de Engenharia de São Carlos, Universidade de São Paulo, São Carlos, 2006.

EN 1991-1-1, Eurocode 2: Design of concrete structures - Part 1-1: General rules and rules for buildings. European standard, 2004.

IYER, P. K.; SAM, C.. Nonlinear finite element analysis of reinforced concrete four-pile caps. International Journal of Structures, v. 15, n. 1, p. 18-34, Jan/Jun, 1995.

KACHLAKEV, D.; MILLER, T; YIM, S.; CHANSAWAT, K.; POTISUK, $T$.. Finite element modeling of reinforced concrete structures strengthened with frp laminates. Final Report, Oregon Department of Transportation, May, 2001.

LIMA JÚNIOR, H. C.. Avaliação da ductilidade de pilares de concreto armado, submetidos a flexo-compressão reta com e sem adição de fibras metálicas. Tese (Doutorado), Escola de Engenharia de São Carlos, Universidade de São Paulo, São Carlos, 2003. 
MAUTONI, M.. Blocos sobre dois apoios. São Paulo, Grêmio Politécnico, 1972.

MIGUEL, G. M.. Análise experimental e numérica de blocos sobre três estacas. Tese (doutorado) - Escola de Engenharia de São Carlos, Universidade de São Paulo, São Carlos, 2000.

MONTGOMERY, D. C.. Design and Analysis of Experiments Fourth Edition. Arizona State University, John Wiley \& Sons, 1996.

MONTOYA, P.J.; MESEGUER, A.; CABRE, M. Hormigon Armado 14.a Edición Basada em EHE ajustada al Código Modelo y al Eurocódig. Barcelona, Gustavo Gili, 2000.

NIESEN, M. P.. Limit analysis and concrete plasticity. PrenticeHall series in Civil Engineering, Englewood Cliffs, New Jersey, 420 p.m 1984.

OSANAI, Y.; WATANABE, F.; OKAMOTO, S.. Stress transfer mechanism of socket base connections with precast concrete columns. ACl Structural journal, v. 93, n. 3, p. 226-276, May/June, 1996. 